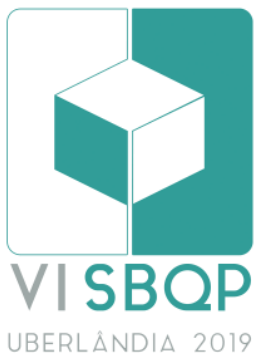

\title{
APARTAMENTOS CONTEMPORÂNEOS: UMA ABORDAGEM DA ERGONOMIA
}

\author{
CALVET, Juliane \\ Universidade de Brasília - Unb, email: arq.julianecalvet@gmail.com \\ ABRAHÃO, Julia \\ Universidade de Brasília - Unb, e-mail: julia.abrahao@gmail.com
}

\begin{abstract}
RESUMO
Edifícios de habitação vertical tem caracterizado a paisagem urbana das cidades brasileiras, visando, não somente diminuir o déficit habitacional, mas sobretudo fomentar a indústria da construção civil. Segundo o Instituto Brasileiro de Geografia e Estatística (IBGE, 2010), houve um crescimento de $43 \%$ na produção de apartamentos depois do ano de 2000. A produção desses edifícios demarca uma mudança na paisagem das cidades e do modo de viver dos seus habitantes. O presente estudo tem como objetivo analisar características morfológicas (geométricas) relacionadas à maneira como as pessoas interagem nesses espaços, buscando identificar a qualidade ambiental face ao comportamento do usuário. Os parâmetros adotados na analise, visam avaliar a qualidade do ambiente construído. Para tanto, são analisadas a configuração espacial, as apropriações e intervenções dos moradores no interior dos apartamentos, assim como as formas de uso das moradias e ocupação pelas pessoas nos espaços. Os procedimentos metodológicos adotados de natureza qualitativa, resultam da articulação entre ergonomia e arquitetura visando avaliar os apartamentos selecionados propondo elementos de referência, como suporte aos arquitetos, durante o processo e gestão de projeto. Os resultados obtidos apontam apropriações diferenciadas dos espaços de morar por parte do usuário contemporâneo.
\end{abstract}

Palavras-chave: Verticalização, Ergonomia, Qualidade habitacional, Mercado imobiliário, Apartamentos contemporâneos.

\begin{abstract}
Vertical residential buildings have characterized the landscape of Brazilian cities, aiming not only to reduce the housing deficit, but mainly to promote the construction industry. According to the Brazilian Institute of Geography and Statistics (IBGE, 2010), there are about 6.1 million apartments in Brazil, representing a $43 \%$ growth when compared to the data of 2000. The production of these buildings marks the change of the urban landscape, as it being one of the main ways of contemporary living. The present study aims to analyze morphological (geometric) characteristics related to how people interact in spaces, seeking to identify the environmental quality and the end-user behavior. Therefore, the configuration of socio-spatial priorities (residents' appropriations and interventions) inside the apartments, as well as usage information of dwellings and permanence of people (occupation) in the spaces are parameters to assess the quality of the built environment from physical factors to the psychological. The methodological procedures allow ergonomic articulation with living spaces in order to evaluate the selected apartments and propose reference elements, such as support to architects during the process and project management. The obtained results demonstrate inadequacies in the living spaces by the end user.
\end{abstract}

Keywords: Verticalization, Ergonomics, Housing quality, Real estate market, Contemporary apartments.

CALVET, J.; ABRAHÃO, J. Apartamentos contemporâneos: uma abordagem da Ergonomia. In: SIMPÓSIO BRASILEIRO DE QUALIDADE DO PROJETO NO AMBIENTE CONSTRUÍDO, 6., 2019, Uberlândia. Anais... Uberlândia: PPGAU/FAUeD/UFU, 2019. p. 966-973. DOI https://doi.org/10.14393/sbqp19089. 


\section{INTRODUÇÃO}

Novas tendências comportamentais e novos modos de vida têm gerado mudanças no cotidiano doméstico e, consequentemente, nos espaços destinados à habitação.

Considera-se, neste estudo, mudanças da sociedade contemporânea, em que a habitação coletiva vertical assume papel preponderante na produção das cidades além de delinear novos modos de vida. Essas premissas estão associadas às mudanças nas estruturas familiares e na revolução técnicoinformacional, levando a novas configurações morfológicas do ambiente construído.

Segundo o Instituto Brasileiro de Geografia e Estatística (IBGE, 2010), há cerca de 6,1 milhões de apartamentos no Brasil, perfazendo um crescimento de $43 \%$ quando comparado aos dados de 2000. Neste contexto, observa-se a o aumento da demanda de novas construtoras/incorporadoras que tem investido em edifícios de habitação coletiva, visando muito mais a rentabilidade do que, de fato, a melhoria da unidade habitacional e tampouco melhor qualidade de vida urbana.

As pesquisas em APO (avaliação pós ocupação) concentram-se nas falhas do ambiente físico pelas suas próprias evidências, talvez pela maior familiaridade em lidar com fatores objetivos do que com a complexidade de avaliação do comportamento humano. Portanto, "na medida em que a APO requerer, para a sua implementação, ambientes qualificados (contemplando o mobiliário e sua infraestrutura, já em uso), a importância e a necessidade de investigar as interfaces APO - AEAC (Analise ergonômica do ambiente construído - aqui incorporando, os conhecimentos sobre Ergonomia), ficam bastante evidentes" (ORSTEIN, 2017).

Para tanto, podemos afirmar que a ergonomia está estreitamente relacionada ao espaço, buscando soluções de projeto e adaptações de forma a assegurar o conforto integrando as características da população tanto quanto às exigências de uso, quanto ao dimensionamento do espaço. Pode-se dizer que a Ergonomia vai além de uma necessidade teórica ou formal e a evolução dos conhecimentos gerados por ela se apoiam em métodos e técnicas de análise própria.

Tendo em vista o modo de morar contemporâneo, o presente estudo tem como objetivo articular os pressupostos da Ergonomia do ambiente construído com os da Avaliação Pós Ocupação - APO, a fim de desenvolver uma Análise Ergonômica do Morar.

A partir dessas considerações pretende-se, apresentar os resultados de um estudo piloto realizado em um edifício de apartamentos destinado à classe média na cidade de Goiânia-GO. Trata-se, portanto, de uma reflexão sobre a pertinência de um instrumento, parte de um estudo maior.

\section{AVALIAÇÃo PÓS OCUPAÇÃO DO ESPAÇO HABITÁVEL}

De acordo com a revisão da literatura, a adoção de multimétodos, interdisciplinaridade e abordagens não convencionais são possibilidades metodológicas de uma APO habitacional. Segundo Villa e Ornstein (2016), "para que os complexos problemas de pesquisa e aplicações na área do 
Ambiente-Comportamento fossem compreendidos, fez-se necessária a aceitação tanto de métodos quantitativos como qualitativos, configurando o que se convencionou de múltiplos métodos".

Para Orstein (2005), "vários autores - Marcus e Francis (1990), Sanoff (1991) e Zeisel (2006) - utilizam métodos científicos e ferramentas para fazer levantamentos, análise de dados e apresentação de resultados, como entrevistas, questionários, escalas de valor, a questão de amostragem e as diferentes categorias de usuários- usuais nas Ciências Sociais, para distintos estudos".

Na literatura, Orstein (2004) também apresenta uma relação dos principais métodos e técnicas utilizadas em termos de APO: Vistorias técnicas/ Walktrough com checklist/ aspectos construtivos e funcionais; medições das condições de conforto ambiental, funcional e ergonométrico; registros visuais; observações de atividades, de comportamentos dos usuários e de ambientes; elaboração de mapas comportamentais; entrevistas semiestruturadas com pessoas-chave sobre o processo de produção, uso, operação e manutenção; entrevistas estruturadas com usuário-chave; questionário para aferição da satisfação do usuário contemplando questões com respostas múltipla escolha/ escala de valores e respostas abertas; grupos focais e, desenhos representativos da percepção ambiental (ORNSTEIN, 2004, p.234).

Na última década, novos enfoques foram somados às análises tradicionais da APO, como "abordagens estético-visuais, baseadas em análises tipológicas e morfológicas; abordagens visuais relacionadas à semiótica; abordagens sintáticas, que relacionam usos à forma dos ambientes; abordagens perspectivas, que envolvem imagens e outras representações de usuário/ambiente (VILLA; ORNSTEIN, 2016).

Atualmente é possível identificar em estudos da área diferentes metodologias que visam avaliar os projetos habitacionais. Tais metodologias fundamentamse em critérios quantitativos, qualitativos e comparativos. Em geral, os projetos são analisados por diferentes temas, tais como inserção urbana, composição, estética, sustentabilidade, tecnologia, sistemas construtivos, além de economia, diversidade, densidade, entre outros (NAGLE; RAPPL; MEDRANO, 2013).

Questões relacionadas a interdisciplinaridade e significativas contribuições às questões ambientais são ferramentas importantes para essa pesquisa. Segundo Villa e Ornstein (2016), atividades participativas e colaborativas envolvendo partes na avaliação procuram antecipar sistematicamente, capturar e resolver questões de uso do edifício, a fim de oferecer soluções de projetos funcionalmente melhor e mais sustentáveis. Essa cultura torna 0 projeto mais assertivo, reconhecendo e validando posturas e agendas de avaliação tanto de desempenho como pós-ocupacionais fundamentais ao processo.

A avaliação do desempenho do ambiente construído deveria ser uma atividade rotineira do arquiteto e urbanista, visando a produção de ambientes com qualidade. Além disso, a APO em edifícios pode colaborar com a diminuição do custo geral da obra, economia dos custos de reparo, além de otimizar o tempo gasto com a solução de problemas que poderiam ser evitados. 


\section{ERGONOMIA: UM NOVO PARADIGMA AO ESTUDO DO ESPAÇO HABITÁVEL}

O surgimento da habitação coletiva vertical coincide com o impulso industrial das cidades brasileiras sendo a expressão de modernidade para a urbanização do século passado. O espaço de morar, muito mais do que adequar-se às funções domésticas, possibilita também traçar um perfil social e antropológico da sociedade, em mudanças comportamentais, novos programas, e aspectos arquitetônicos específicos, tais como: forma, estilo, materiais, técnicas construtivas, entre outros (TRAMONTANO, 1998).

Ao longo dos últimos anos as contribuições dos ergonomistas podem ser descritas como tentativa de intervir o quanto antes nos projetos. Inicialmente se deu nos espaços de trabalho que foram além dos postos de trabalho, abordando a reflexão sobre implantação, renovação e transformações das edificações industriais. "Mostrou desse modo aos projetistas que as formas e volumes das fábricas se determinam tanto a partir dos meios humanos, quanto dos técnicos" (Lautier, 1999). Na década de 1980, o surgimento das equipes interdisciplinares significou a associação de conhecimentos complementares e promoveu a entrada dos ergonomistas na arquitetura.

A ergonomia tem sido convocada a colaborar com os arquitetos de diferentes formas. Desde cedo, percebeu-se a necessidade de atuar a montante do processo de projeto, antes que sejam tomadas decisões irreversíveis ou que aumentem o custo das adequações (DANIELLOU, 1988).

Enquanto metodologia, a Ergonomia pressupõe a utilização de distintas técnicas, cuja importância para análise depende da problemática e da configuração da demanda. As observações globais e sistemáticas naturalmente adquirem um espaço privilegiado na intervenção. No entanto, outros instrumentos são frequentemente adotados ao longo do percurso metodológico, entre eles entrevistas e questionários (ABRAHÃO, 2009).

A metodologia da AET não deve ser considerada como uma série de procedimentos a serem aplicados um após o outro. Trata-se de assegurar a possibilidade de ajustes e regulações introduzidas durante toda a ação na busca da qualidade dos resultados, isto é, uma transformação efetiva, que pode ser avaliada em termos de satisfação dos usuários.

Considera-se na ação ergonômica as seguintes fases: análise da demanda; coleta de informações sobre a empresa; levantamento das características da população; escolha das situações de análise; análise do processo técnico e da tarefa; observações globais e abertas da atividade; elaboração de um pré-diagnóstico - hipóteses explicativas de nível 2; observações sistemáticas análise dos dados; validação; diagnósticos; e recomendações e transformação. Cada uma dessas fases deve integrar as bases da abordagem ergonômica que pressupõe: estudo centrado na atividade real de trabalho; globalidade da situação de trabalho; e consideração da variabilidade, tanto a decorrente da tecnologia e da produção quanto a dos trabalhadores (ABRAHÃO, 2009).

A ação ergonômica em projetos de apartamentos pressupõe, além da construção técnica a partir da análise da atividade, uma construção social, ou seja, uma estrutura participativa de projeto, fundada no envolvimento dos usuários e demais responsáveis pelo espaço, contribuindo para uma qualidade habitacional. 


\section{MÉTODO DO ESTUDO}

A APO e a AET, são metodologias com objetos de análises diferentes. Enquanto o "objeto central da APO é avaliação do uso dos ambientes construídos, entendido como forma de apropriação dos espaços, operação e manutenção" (ORNSTEIN; RÓMERO, 1992, p. 13), o objeto central da AET é atividade inserida em uma conjunção social de demandas que orientam a análise (DANIELLOU, 2004).

Ao mesmo tempo em que as duas metodologias são verdadeiramente distintas, há certa afinidade entre elas por causa do trajeto inverso que as aproxima do objeto de cada uma: a APO, aproxima-se da noção da atividade enquanto categoria mediadora e reguladora da relação usuárioambiente construído; a AET, por sua vez, por meio da atividade, aproxima-se do projeto do ambiente construído.

A natureza interdisciplinar da ergonomia e da arquitetura constitui a base desta pesquisa, considerando que a abordagem ergonômica possibilita uma análise fina do habitar enriquecendo os parâmetros e metas a serem integrados no projeto conforme as necessidades dos usuários.

Apoiada nos pressupostos da ergonomia, a metodologia do estudo tem como objetivo revelar facetas e características do modo de vida contemporâneo, que vem se modificando ao longo do tempo. Esta mudança será analisada em apartamentos de tipologias de 3 quartos, procurando identificar continuidades, alterações e adaptações (tanto pelo setor imobiliário como pelos moradores), explicitando transformações no espaço doméstico e no modo de vida contemporâneo. Serão investigadas moradias verticais, onde a atividade (uso do espaço doméstico) é o eixo norteador do processo de investigação, pois permite que os aspectos das condições físicas do espaço sejam resultantes das atividades existentes ou futuras.

A coleta de dados do estudo piloto ocorreu por meio de um questionário. Os aspectos considerados foram: Localização do apartamento, tipo de ocupação do imóvel e metragem; renda familiar e grau de escolaridade; tipologia familiar; faixa etária; atividades desenvolvidas/ uso; adequação/ reforma do espaço às novas solicitações emergentes da sociedade; índices de satisfação dos usuários moradores. Ao final do questionário, solicitou-se um croqui, para os moradores desenhar as modificações realizadas ou desejadas no apartamento. Os questionários foram aplicados com o intuito validar o instrumento visando aproximação com o usuário tendo como referência seu modo de morar.

\section{O ESTUDO DE CASO}

O edifício selecionado (Figura 01) está localizado em uma das principais áreas privilegiadas da cidade de Goiânia-GO. Passou a ser alvo dos empreendedores imobiliários, à medida em que a legislação urbanística liberou o gabarito próximo a um parque urbano, agregando valor ao metro quadrado, reforçando o conceito de arranha-céus e modernidade na produção do espaço doméstico. Representa atualmente a região mais valorizada da cidade.

A tipologia dos apartamentos do estudo de caso é de três quartos por unidade habitacional com área útil de $139 \mathrm{~m} 2$ (Figura 02). O edifício possui 33 
andares, 04 apartamentos (02 duplex e 02 tipos) por andar. Os questionários foram inseridos nas caixas de correio apenas dos apartamentos tipo (66 unidades), característica adotada na pesquisa. Buscou-se identificar o que os usuários consideram qualidade habitacional tendo como referência sua moradia.

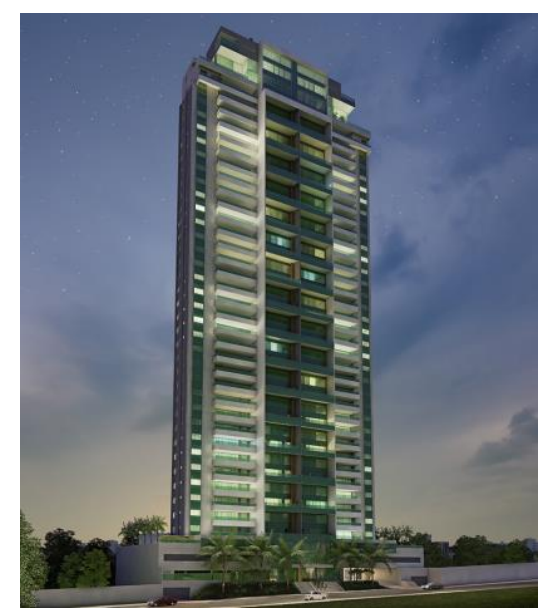

Figura 1 - Fachada Estudo de Caso -

Fonte: $<$ http://hsincorporadora.com.br/empreendimentos/reserva-marista>.

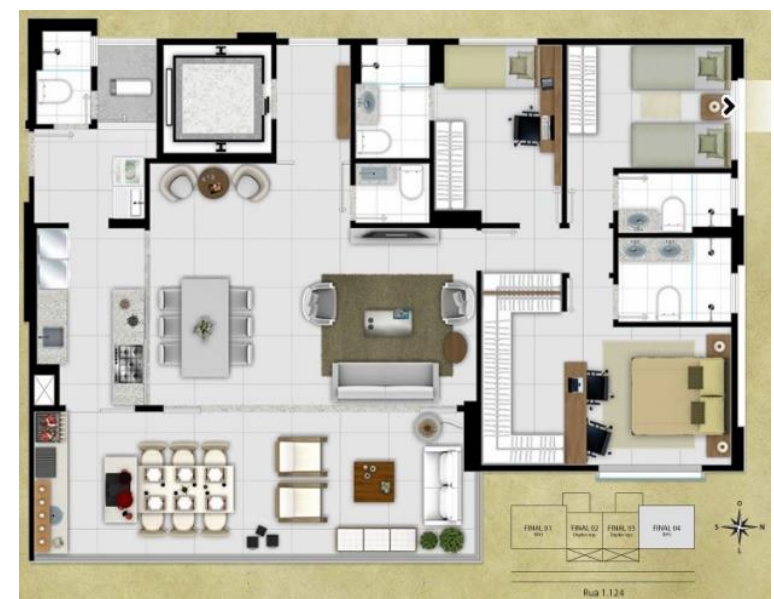

Figura 2 - Planta Estudo de Caso -

Fonte: <www.hsincorporadora.com.br/reserva/plantas.php>.

\section{RESULTADOS}

Embora, apenas $20 \%$ dos questionários terem sido respondidos, foi possível perceber insatisfações e pontos positivos do apartamento. Inicialmente identificou-se as características dos moradores: renda familiar de mais de 10 salários mínimos, tipologia familiar variada (pessoa só, homoafetiva, família nuclear e monoparental), grau de escolaridade superior e a maioria dos habitantes possuem unidade própria. Por mais que haja uma padronização nas soluções projetuais de edifícios de habitação coletiva nos últimos anos, algumas especificidades dos usuários não foram contempladas, uma vez que alterações ocorreram após a apropriação do espaço, como por exemplo a área de serviço, juntamente com a laje técnica. A questão de maior índice (15\%) de insatisfação foi da acústica, sendo os ruídos por parte dos vizinhos. Minoria dos moradores (2\%) apontaram que gostariam de ampliar a suíte de 
casal e fazer trocas de materiais, como pisos e bancadas). Os pontos positivos apontados foram a varanda e a churrasqueira, com setorização privilegiada e metragem satisfatória. Apenas 2 (dois) moradores fizeram o croqui solicitado, mas não conseguiram expressar por meio do desenho as modificações executadas e/ou desejadas.

\section{CONSIDERAÇÕES FINAIS}

Parte-se do pressuposto de que não há um modelo ideal de apartamento ainda que este seja o discurso recorrente por parte dos investidores. Observase que as inovações, novos espaços coletivos e, inclusive, a adoção de discursos atrelados à sustentabilidade ou à cidade estão muito mais vinculados ao sucesso do empreendimento enquanto produto imobiliário do que, de fato, atender às exigências de cada um dos usuários finais.

As avaliações pós-ocupação colaboram com as fases de síntese e correção das falhas de projeto. Métodos e técnicas de avaliação do ambiente construído são utilizados por pesquisadores vindos de diferentes áreas. A avaliação pelo próprio usuário de uma edificação é considerada importante no levantamento da complexidade do uso e da satisfação do ambiente construído. As pesquisas de APO têm assumido cada vez mais o seu caráter interdisciplinar (ZEISEL, 2006).

Alguns trabalhos já concluídos sugerem que há uma grande necessidade de sistematizar e aprofundar esses dados com o objeto de subsidiar 0 desempenho funcional dos edifícios (ORNSTEIN; CRUZ, 2000). Sendo assim, é importante o aprimoramento metodológico das APO em edifícios de apartamentos focando a funcionalidade dos espaços propostos e 0 comportamento dos usuários. Os resultados do estudo piloto apresentados nessa pesquisa foram considerados o início de uma pesquisa maior, a fim de aprimorar uma metodologia que busca elaborar uma Análise Ergonômica do Morar.

\section{REFERÊNCIAS}

ABRAHÃO, J.; SZNELWAR, L.; SILVINO, A.; SARMET, M.; PINHO, D. Introdução à Ergonomia da prática à teoria. São Paulo: Blucher, 2009.

BRASIL. INSTITUTO BRASILEIRO DE GEOGRAFIA E ESTATISTICA. Censo Demográfico 2010. 2012. Disponível em: <http://censo2010.ibge.gov.br/>. Acesso em: 13 dez. 2012.

DANIELLOU, F. Ergonomie et projets industriels, Apostila do curso B4, Laboratório de Ergonomia e Neurofisiologia do Trabalho, CNAM, Paris, 1988.

DANIELLOU, F. A ergonomia em busca de seus princípios debates

epistemológicos. In: A ergonomia em busca de seus princípios debates epistemológicos. 2004.

NAGLE, C. B.; RAPPL, K.; MEDRANO, L. S. Métodos de análise de projetos habitacionais: Uma discussão sobre o método I+ D+ VS. Gestão \& Tecnologia de Projetos, v. 8, n. 2, p. 105-115, 2013.

ORNSTEIN, S. W.; ROMERO, M. A. Avaliação pós-ocupação (APO) do ambiente construído. 1992 
ORNSTEIN, S. W.; CRUZ, A. O. Análise de desempenho funcional de habitações de interesse social na grande São Paulo. ENCONTRO NACIONAL DE TECNOLOGIA DO AMBIENTE CONSTRUÍDO, v. 8, p. 1439-1446, 2000.

ORNSTEIN, S. W. Gestão da Qualidade na Construção Civil e o Desenho Universal. Novos rumos para Avaliação Pós-Ocupação (APO) aplicada no desenho urbano. In: Seminário Acessibilidade no Cotidiano: Rio de Janeiro, 2004.

TRAMONTANO, M. C.; TASCHNER, S. P. Novos modos de vida, novos espaços de morar, Paris, São Paulo, Tokyo: uma reflexão sobre a habitação contemporânea. 1998.

VILLA, S. B.; ORNSTEIN, S. W. Qualidade ambiental na habitação-avaliação pósocupação. São Paulo: Oficina de Textos, 2016.

ZEISEL, J. Inquiry by design. Environment/behavior/neuroscience in architecture, interiors, landscape, and planning, 2006. 